\title{
HACIA UNA SOCIOSEMIÓTICA DE LA CULTURA: LANDOWSKI Y LA SOCIEDAD FIGURADA*
}

\author{
JUAN LUIS JIMÉNEZ RUIZ \\ (Universidad de Alicante)
}

\begin{abstract}
RESUMEN
Semantic, Syntax and Pragmatic represent in themselves three different approaches to the same concern: semiotic structure.

The aim of this paper is to provide a general view of Landowskian Semiotics, discussing the results achieved from different fields of knowledge to the same object and showing the relations between language and power.
\end{abstract}

Lejos de permanecer aislada en reflexiones formales que garanticen el estatuto cientificista y objetivo en el acercamiento al carácter sistemático de su objeto de estudio e investigación, la lingüística, en otros tiempos dedicada a la formulación de taxonomías sin tener en cuenta el carácter social y, consecuentemente, humano de su propio objeto, asiste hoy en día a una actitud mucho más abierta que le permite acercarse a los modos de comportamiento lingüisticosociales (VILLENA, 1992, pp. 125 y ss.). Y no porque los sociólogos se hayan dedicado especialmente a aspectos estadísticos relacionados con estudios temáticos, exámenes de vocabulario y análisis de las figuras que expresan las posiciones sociales - recogiendo, en el fondo, la concepción de la lengua como un dato (TRUDGLL, 1978, pág.3) -, sino por la necesidad

\footnotetext{
- Agradecemos al Dr. Landowski el envío de su libro La sociedad figurada. Ensayos de sociosemiótica, F.C.E.-Universidad Autónoma de Puebla, México, 1993, 295 págs., y la oportunidad que nos ha brindado de realizar esta pequeña reflexión.
} 
de dar una explicación coherente tanto del funcionamiento global como de la eficacia social del discurso'.

Quizá en otros tiempos, esta necesidad se habría visto solapada por el voluntarismo consciente de mímesis con otras parcelas más «cientificistas» del saber, en busca de la autoconfirmación de la ansiada - y no menos deseada — ruptura epistemológica, atribuida a la linguiística de herencia saussuriana 2 . Pero actualmente, en un contexto en el que la lengua amplía la función dialógica y, hasta cierto punto privada, que permitía el contacto entre un emisor y un receptor para la transmisión de un mensaje -cuyo soporte principal era el lenguaje-, a una función panlógica en la que tanto emisores como receptores han perdido ese carácter privado $\mathrm{y}$, hasta cierto punto unitario, en pro del carácter público y colectivo - inherente a la propia sociedad de masas en la que vivimos (MARTINEZ ARNALDOs, 1990)-, podremos comprender la transformación del lenguaje objeto en lenguaje sujeto (JIMÉNEZ RuIZ, 1994a), auténtico sistema de significación que no sólo refleja sino, lo que es más importante, «construye» todo el complejo entramado social.

Según esta concepción, no es lo real loque permite significar al lenguaje; sino que es el lenguaje en tanto que realidad relativamente autónoma el que nos permite «hacer» significar a lo real, dando al mundo la apariencia de un objeto significante.

Ello exige, obviamente, no sólo una reformulación de la reflexión lingüística sobre el significado, que, alejándose de planteamientos taxonómicos y atomistas, reivindique la importancia del discurso en cuanto totalidad significante ${ }^{3}$, sino también una conciencia crítica sobre este lenguaje que nos rodea, con el fin de poder llegar a una sociedad flexible, que nos libere de la semantización del léxico y nos permita, gracias a la comprensión del lenguaje, la huida de la manipulación política, cultural y económica. No en balde, la historia de los comportamientos y actitudes del hombre, que no se miden en función de los hechos sino de los sentidos (lingüísticos) de esos

1 El estudio del significado construido en la interacción es producto de la suma y síntesis de técnicas procedentes de direcciones muy dispares; entre otras, la sociología subjetivista y fenomenológica, que pretende el conocimiento de los procesos de socialización y de formación personal a través de la lengua (CARABaña y LAMo, 1978); la filosofía de los actos de habla, con insistencia en los desarrollos pragmáticos posteriores a la síntesis de SEARLE (1979) y otros; la etnografía de la comunicación, como fuente de los análisis conversacionales y manifestación de contrastes interculturales (GUMPER, 1982); la pragmática lingǘística y teorías textuales de fundamento generativo (Brown Y LeVInson, 1987); los análisis del contenido (PtZARRo, 1979) y los estudios sobre la enunciación (ACHARD, 1983); o los análisis del discurso (MAINGUENEAU, 1987); por poner unos casos.

2 Nos referimos al siglo XIX en el que se produce el doble triunfo del positivismo y del idealismo especulativo, partidario el primero de un realismo empírico y el otro de un realismo trascendente, que conducirían al abandono de la dimensión semiótica de los textos, porque su «letra» iba a quedar confinada en una filosofía positivista y su «espíritu» en hermenéuticas especulativas (RASTIER, 1993a, pp. 63-64).

3 Es lo que la semiótica "greimasiana», en tanto teoría general de la significación, intenta concebiry describir, tal y como manifiesta el propio LANDowsk en una entrevista concedida a Laimonas Tapinas para la revista Santara, Vilnius, Lituania, 1993, y traducida por Raúl DoRRA en Morphé 8 (1993), pág. 146. 
hechos ${ }^{4}$, exige el análisis no de hechos sino de signos (textos) para descifrar en ellos la representación de estas actitudes (LLEDó, 1975).

LENGUA: Función dialógica

(Privada)

LENGUAJE: Objeto
Función Panlógica

(Pública)

Sujeto

En este sentido, Eric LANDowsKI, colaborador de Greimas durante más de veinte años, participante regular desde 1967 en el Seminario de la Escuela de Altos Estudios en Ciencias Sociales de París, director desde 1979 de las publicaciones del grupo de investigación semiótica que Greimas fundó y redactor en jefe de Actes sémiotiques y Revue internationale de sémiotique juridique, $\mathrm{y}$, actualmente, investigador del Centre d'Étude de la Vie Politique Française, nos ofrece ahora la versión española de La sociéte réfléchie, en una coedición llevada a cabo por la Universidad Autónoma de Puebla y el Fondo de Cultura Económica.

La sociedadfigurada. Ensayos de sociosemiótica constituye, pues, un acercamiento serio y riguroso al discurso como un objeto de conocimiento en el marco de la problemática general de la dinámica de las relaciones entre el poder y el lenguaje, atendiendo a su capacidad de «actuar» $\mathrm{y}$ «hacer actuar» y a las interrelaciones que con su ayuda se producen entre los sujetos individuales o colectivos.

Aunque este acercamiento sólo sea posible en el marco de una teoría linguística, el creciente deseo de buscar la especificidad tanto en el objeto como en el método, que ha llevado a la lingüística desde un punto de vista glotológico a una gran diversidad de tendencias, conduce a LANDowskr al rechazo tanto de la teoría lingüística stricto sensu - por la definición misma de su objeto y la exclusión de la contextualización de los hechos de lenguajes - como de la teoría pragmática - por la carencia del aparato metodológico unificado capaz de dominar las diferentes variables contextuales-, adoptando consecuentemente, la teoría semiótica general como retotalización (SUMPF, 1968,pp. 6y ss.) y marco epistemológico adecuado para

4 Es la tesis que fundamenta la concepción sociolingüística de la historia que defendemos, cuyos fundamentos epistémicos para su aplicación a la historia de la lengua pueden verse en JimÉNEZ RuIz, 1994b.

$s$ De hecho, el estudio del sentido textual excede de la lingǘstica inmanente, puesto que la lengua es sólo el instrumento del sentido, debiendo ocuparse de ello una disciplina más amplia (Cifuentes, 1994, pág. 143). 
la interpretación del objeto ${ }^{6}$.

Las razones pueden comprenderse fácilmente, puesto que la semiótica se ha ocupado de los hechos como efecto del sentido del lenguaje y, además, ha trascendido el ámbito taxonómico acercándose al interior de las estructuras y de los procesos de significación no sólo individuales, subjetivos y particulares, sino también sociales, objetivos y solidarios (KoRNBLrT, 1984, pp. 8 y ss.).

Desde un punto de vista intradisciplinar, también se podrían establecer diferentes líneas de demarcación que orientasen la adopción metodológica. Es lo que hace LANDOWSKI al distinguir tres generaciones - que no son cronológicas ni opuestas sino complementarias 7 - dentro del ámbito semiótico; a saber, una primera generación de la semántica, cuyos investigadores - principalmente del dominio de la semántica estructural (COSERIU, 1977; GREIMAs, 1977; LyONS, 1980, pp. 230-315), la antropología estructural (LÉVI-STRAUSS, 1976) y el análisis estructural del relato (BARTHES, 1982)parten de la necesidad de describir los estados de equilibrio del sistema «antes de conocer y comprender cómo los sistemas se transforman y a su vez transforman los agentes que los manipulan»; una segunda generación de la sintaxis, formada por un conjunto de estudiosos preocupados por la dinámica de las relaciones intersubjetivas constitutivas del cambio social; $\mathrm{y}$, finalmente, una tercera generación de la pragmática, que, bajo los presupuestos de la teoría de la enunciación (RECANATI, 1981), aporta la nueva problemática de las relaciones entre el discurso y su contexto (LyoNs, 1983, pp. 197 y ss.), con el fin de precisar la eficacia pragmática del discurso ${ }^{8}$.

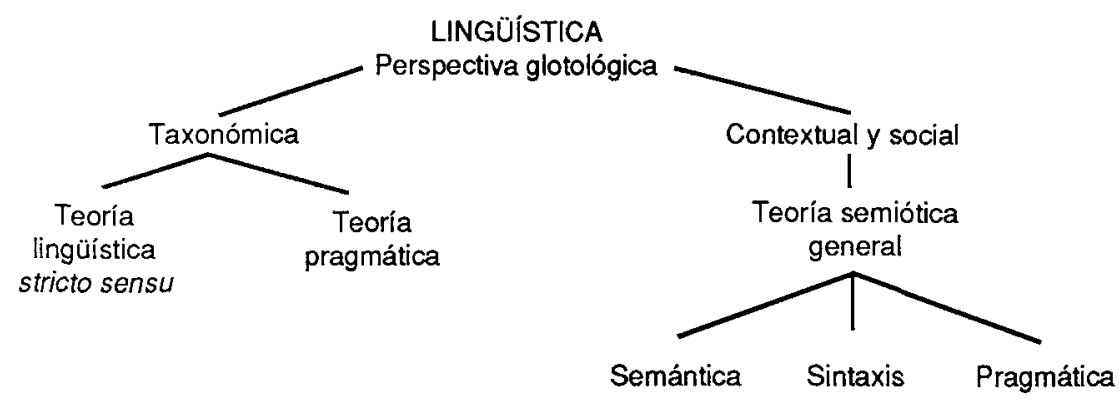

- Con todo, la sociosemiótica textual propuesta por LANDowski y basada en los presupuestos greimasianos, no debe entenderse opuesta en modo alguno a los planteamientos pragmáticos; se trata de propuestas complementarias y, hasta cierto punto, homologables (CIFUENTES, 1990; PARRET, 1983).

En definitiva, se trata en Landowski de una división metodológica o práctica, que no asume el estatuto teórico que según RASTIER (1991, pág. 82) ha llevado a la lingüística actual a uno de sus principales problemas epistémicus; sobre la tríada semiótica y su desarrollo teórico vid. Cifuentes, 1994, pp. 113 y ss.

${ }^{8}$ Obviamente, subyace en el fondo la consideración de que el significado social no es una modificación o una connotación a partir de significados intralingüísticos, sino un producto contextual (Slama-Cazacu, 1970), lo que potencia, como sostiene Villena, 1993, discusiones sobre los fundamentos mismos de la reflexión sobre la sociedad y sus instituciones $\mathrm{y}$, en el caso de LANDOWSKI, el proyecto sociosemiótico que comentamos. 
El texto de LANDOwskI, que engloba en sus 295 páginas trabajos publicados con anterioridad junto a nuevas versiones de otros, constituye el reflejo de la evolución entre las tres generaciones que acabamos de señalar.

En este sentido, todos estos planteamientos, que constituyen el grueso de la introducción del trabajo y que concluyen con la referencia explícita del objetivo último que se pretende así como con la explicación de las tres partes en las que se estructura el libro, presentan el atractivo de permitirnos una doble lectura; a saber, una lineal, que arranca del capítulo I y concluye en el capítulo XII; y otra discontinua, que permite diferentes acercamientos para la comprensión de la propiedad reflexiva que caracteriza a la comunidad social en cuanto signo lingüístico $0^{9}$ que, en definitiva, le permite proporcionar las reglas para su propio juego (v. DuJk, 1980, pp. 241 y ss.).

\section{$2 a$}

La primera de ellas, la lectura lineal, descubre en el texto tres bloques sucesivos: un primer bloque en el que se da cuenta de la construcción de las unidades semióticas que permiten a los actores sociales construirse una identidad (caps. I y II) en el marco de unas relaciones sintácticas definidas, como puedan ser las establecidas en el ámbito del derecho (cap. III). El se gundo bloque organiza la puesta en escena de estos elementos estableciendo las modalidades de comunicación intersubjetiva (cap. IV) y la tipología de los dispositivos de figuración que permiten a los sujetos comunicantes la representación -ya sea en la escena publicitaria (cap. V) o en la política (cap. VI), principalmente-. El tercer y último bloque constituye un acercamiento semiótico a la interacción propiamente dicha, a partir de los mecanismos para hacer creer (caps. VIII, IX y X) y hacer hacer (caps. XI y XII).

La segunda lectura —que hemos denominado de discontinuidades- permite al interesado profundizar en la hipótesis de trabajo que sustenta el libro, para, a partir no sólo de las nociones que integran la comunidad lingüisticosocial; a saber, las de opinión pública (cap. I), generación social (cap. II) y estrategia (cap. XI); sinotambién deciertas categorías problemáticas de uso muy actual —la oposición público/privado

9 La hipótesis de trabajo, por tanto, es la consideración de que el espacio social construido no refleja los datos sociales preexistentes, sino el lugar a partir del cual lo social —como sistema de relaciones entre sujetos- se constituye por medio del pensamiento. 
(cap. IV), la relación representante/representado (cap. IX), entre otras-, construir la gramática del sistema de significación virtual que nos permita organizar las reglas del juego lingüisticosocial y, consecuentemente, comprender mejor el sistema social concreto, una gramática no sólo narrativa, que aclare cómo se construye lo social a partir de las relaciones entre los sujetos, reconstruyendo los esquemas narrativos modales que se encuentran en la base de las configuraciones intersubjetivas (caps. V, VI y VII), sino también discursiva, que examine las condiciones en las que se actualizan esas relaciones entre los sujetos (caps. X, XI y XII).

Como puede comprenderse, ambas lecturas no son contradictorias sino que reproducen dos modos diferentes - pero complementarios- de acercamiento a un mismo objeto; a saber, uno metodológico — basado en la lectura lineal—, que pone de relieve la autonomía objetal de lo social y lo político; y otro ontológico - basado, en esta ocasión, en la lectura discontinua-, que pone de manifiesto la significación lingüistica de las relaciones establecidas entre los sujetos sociales. Y quizá, aquí radique la importancia del libro de LANDOwsKI, al permitimos el estudio social desde este particular planteamiento lingüístico, que arranca con la explicación de la noción de opinión pública.

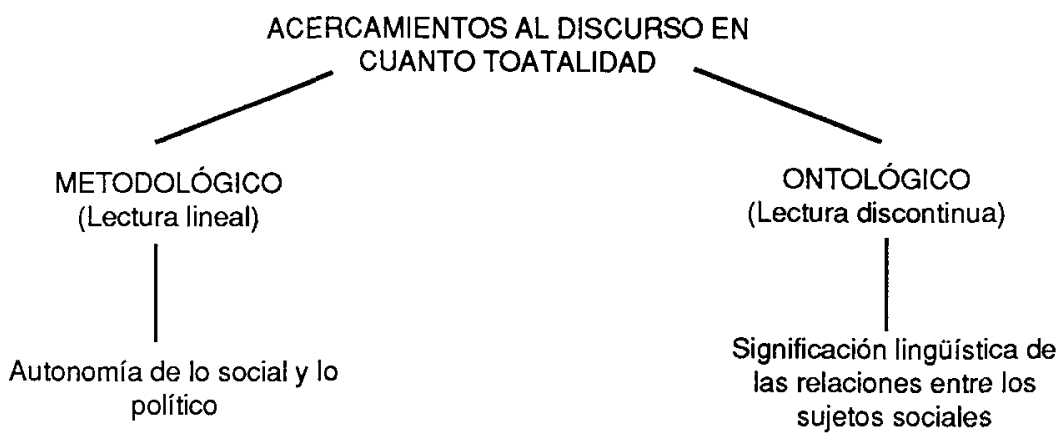

$3 a$

En este capítulo - el primero dal libro-, Eric LANDOwsKI pretende construir la identidad de la opinión pública en cuanto actor lingüisticosocial, atendiendo a sus condiciones de empleo, con el objeto de comprender su uso semiótico, frecuente en los discursos sociopolíticos de masas - ya sea atendiendo a su función narrativa en un discurso enunciado o a su función discursiva en la puesta en escena del acto de la 
enunciación-.

Por ello, tras considerar la importancia del público a la hora de determinar las distintas funciones de la opinión en el teatro político y realizar una magnífica comparación de éste con el teatro griego, pasa a establecer los niveles en los que puede analizarse la realización del sistema actancial de la opinión; a saber, en su función de protagonista de los relatos de manipulación —en cuanto destinador sintáctico encargado de hacer actuar a otros sujetos-, y en su función de agente para el discurso de manipulación.

\section{$3 b$}

La segunda noción que integra la comunidad lingüisticosocial propuesta por LANDOWSKI, la de generación social (cf. cap. II), se explica con el objeto de establecer la estructura conceptual subyacente que nos permita unir la idea de identidad de los sujetos colectivos con un proyecto lingüístico.

Sin lugar a dudas, el carácter dual del lenguaje permite establecer una línea de demarcación entre lo que podría ser una fase interna, que considera las lenguas como entidades ajenas a las relaciones de fuerza simbólica y conflicto social —objetivismoy otra fase social, según la cual los hechos lingüísticos reflejan el dinamismo social que constituye su contenido - humanismo (JIMÉNEz RuzZ, 1993) - , que, a su vez, son reflejos de los dos polos epistémicos que atraviesan esta línea; a saber, el instrumentalista, que considera las lenguas como organismos sistemáticos útiles para la comunicación, y el ideologista, más cercano al análisis de las consecuencias de la identificación del lenguaje y la conciencia (ViLleNA, 1993, 90-92).

Lo verdaderamente importante de todo ello es la auténtica relación ideológica que se puede establecer entre ambas posturas y que permite un enfoque más productivo desde el punto de vista epistemológico.

Así, frente a la historia externa, por ejemplo, que no ve en la lengua más que un hecho cultural, una sobreestructura susceptible de ser explicada por una infraestructura - sociológica, económica, etc.--, un síntoma de una realidad más profunda a la que simultáneamente cubre y manifiesta; o a la historia crítica que, aunque busca las fuentes e influencias ejercidas por los sistemas lingüísticos antecedentes, acaba en un proceso de desmembración del sistema lingüístico, con el que se pierde la unidad de intensidad, la intuición estructural del conjunto de cada sistema; el proyecto de relaciones sintagmáticas entre epistemespropuesto por LANDowski permite al estudioso trascender la mera faceta crítica e ir más allá, oponiendo al movimiento centrífugo del análisis crítico el movimiento centrípeto que le conducirá a la intuición estructural central y unificadora de cada sistema lingüisticosocial, sin ignorar: $\left.1^{\circ}\right)$ que sólo desde la totalidad del proceso histórico tienen sentido las diversas partes del mismo (HEGEL, $\left.1983,225-226) ; 2^{\circ}\right)$ que cada momento de la historia está generado por el anterior y es regenerador del siguiente; y, $3^{\circ}$ ) que este proceso actúa por oposiciones en la que los sistemas lingüísticos no son destruidos sino superados por los siguientes. 
Se trata, consecuentemente, de precisar el sentido que hay que atribuir a los cambios linguíísticos en las distintas posiciones históricas, mediante un doble procedimiento de producción de diferencias - sin las cuales la historia no tendría significación - y de conciliación de opuestos - sin lo cual no habría sentido(JIMÉNEZ RuлZ, 1994b)-.

Por ello, la noción de generación social como principio de organización debe penetrar en el universo simbólico y exigir una explicación más profunda de los hechos lingüísticos, puesto que no se trata ya de buscar las bases sociales de las lenguas a través de la historia ni las circunstancias generadoras sino, tal y como propone Hymes (1975), de establecer las esferas de expresión simbólica de las comunidades lingüísticas a lo largo de la historia 0 , dicho en palabras de LANDOWSKI, de encontrar los sujetos colectivos que llegan a la existencia a partir de un conjunto de símbolos.

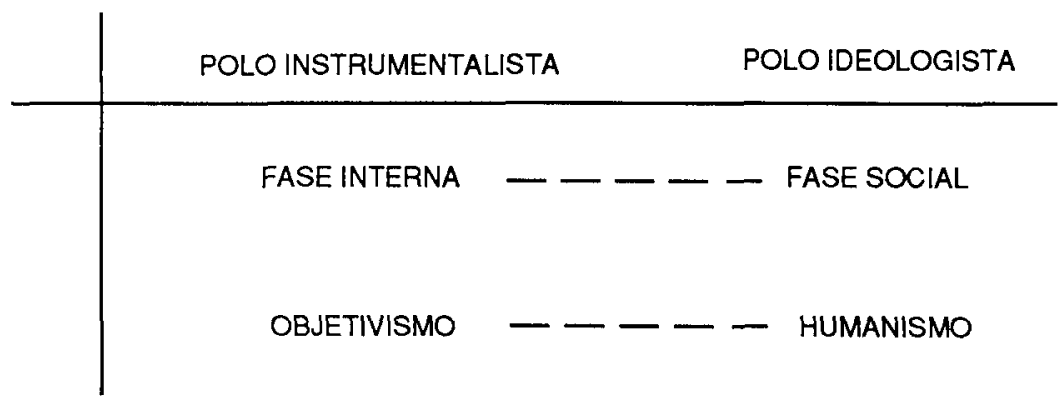

$3 c$

La tercera de las nociones que integran la comunidad lingüística es importante como mecanismo para hacer hacer. Se trata de la estrategia (cf. cap. XI), noción que presupone por definición una situación y ciertos programas de enfrentamiento y maniobra, y que engloba una serie de procedimientos de interacción tendentes

«[...] a la producción de un hacer (o [a la] transformación de un estado) [procedente], en su principio esencial, de un acto totalizador que fusiona singularidades» (pág. 245).

En este sentido, el estratega tiene como tarea la reconstrucción de un todo a partir de la aportación de actantes colectivos sintagmáticos. 
Ello justifica la necesidad de establecer estas modalidades de comunicación intersubjetiva (lectura lineal) precisando una de las categorías organizativas de mayor alcance epistémico - la atravesada por el eje de los polos público y privado (lectura discontinua), que constituye el núcleo del capítulo IV--.

$4 a$

En este capítulo, LANDOWsKI, tras sustituir la discusión sobre los asuntos públicos por el discurso de seducción (BERRIo, 1983, pp. 70 y ss.) y establecer dos tipos de aproximaciones al régimen de visibilidad de los actores sociales en sus distintas funciones; a saber, una de tipo semántico, que considera las «funciones socialmente connotadas [...] surgidas ya sea del régimen de la no visibilidad (la «intimidad»), o del dominio de la comunicación abierta y de la «publicidad»»; y otra de tipo sintáctico, que se basa en el «análisis de la relación de visibilidad considerada en sí misma, independientemente de los contenidos»; llega a la conclusión de que la transgresión de las reglas contractuales que se producen entre los dos polos mencionados pueden determinar situaciones polémicas o estrategias que conllevan una inversión de las posiciones de cada parte.

\section{$4 b$}

Sin pretender aportar ninguna solución definitiva en su deseo de exponer ciertos elementos de conceptualización e interpretación, LANDOwski plantea la reformulación semiótica de otra categoría de uso también muy actual - la relación representante/ representado (cf. cap. IX) - , con el fin de relacionar dos tipos de discursos;

«[...] uno concebido como el discurso del no sujeto (es lo verosímil [...] explícitamente sostenido por lo social), y el otro recibido [...] como el «discurso del sujeto» en el que él «cree»» (pág. 218).

Obviamente, la gramática que nos explique la construcción de lo social a partir de las relaciones actanciales, dando cuenta de las elecciones ideológicas y estratégicas así como de la eficacia social del discurso, va a moverse en el doble plano de la enunciación, en el que se determinarán los roles discursivos posibles tanto del emisor como del receptor, y del propio discurso enunciado, puesto que, en el fondo, al discurso de la simple presentación de los objetos representantes - en el caso publicitario, a la vez «deseados»- se superpone un discurso figurativo secundario 
de representación de los sujetos —en el caso publicitario, también «deseantes»-10.

Ello justifica el papel de la esquematización narrativa en cuanto organización formal de nuestro propio deseo y la necesidad de un relato de búsqueda como modelo subyacente de la puesta en las escenas publicitaria (cap. V), periodística (cap. VI) y política (cap. VII) de las diferentes relaciones sociales.

En este sentido, como reconoce explícitamente el propio LANDOwsKI, no propone una lectura monolítica sino una propuesta de interpretación, cuya validez principal pudiera estar en recoger las nuevas formas de intersubjetividad y de sociabilidad que se encuentran en los diferentes discursos analizados y que permiten a los sujetos comunicantes la representación.

Este reconocimiento y sistematización de regularidades que permitió laconstitución progresiva de la gramática narrativa se completa con el estudio de la puesta en discurso de las estructuras semionarrativas, con el objeto de examinar las conclusiones en las que se actualizan las mismas ${ }^{11}$. Se trata, a largo plazo, de la construcción de una teoria general del hacer y, en el caso que ocupa a LANDOwsKI de momento, de una semiótica de la (inter)acción (cap. VIII).

«Mientras que, esquemáticamente, se vuelve así tarea de la gramática narrativa programar y regularizar el sentido del espectáculo que se intercambian entre sí los sujetos con el fin de interactuar recíprocamente [...] no se puede, por otro lado, dejar de mencionar una segunda componente del «aparato formal de la enunciación», la cual incluirá toda la variedad de los elementos que provienen de la gramática discursiva» (pág. 231).

Consecuentemente, el rol de la puesta en el discurso es, precisamente, el de transformar las posiciones virtuales que el componente narrativo ofrece a los actantes de la comunicación. Es la dimensión política que, según LANDOWSKI, caracteriza todo hacer discursivo.

Fiel a las ideas greimasianas, el texto de LANDowsKI, lejos de ser simplemente un

10 No en balde, el sentido de un enunciado, tal y como afirma Ducrot (1984, pág. 140), es la propia descripción de su enunciación.

11 Ello está relacionado con lo que RASTIER denomina orden hermenéutico, que engloba fenómenos de comunicación y factores pragmáticos inseparables de la situación histórica y cultural de la producción y la interpretación (RASTIER, 1993b, pp. 30-31). 
ejercicio de reflexión epistemológica y de construcción hasta cierto punto teórica ${ }^{12}$, constituye una auténtica mirada operatoria de nuestra relación con el mundo político, periodístico y publicitario-, un proceso que, aunque basado teórica y metodológicamente en la lingüística, delimita su objeto del que le corresponde a la linguiística del discurso, para dar cuenta de manera coherente y sistemática de las condiciones de la producción y de la aprehensión de la significación a partir de categorías generales, como puedan ser la oposición público/privado o la relación representante/representado, por poner unos $\operatorname{casos}^{13}$.

En el fondo - y en la forma-, LANDowski ha presentado de manera sistemática la problemática de la política en su sentido más genérico, es decir

«[...] como espacio de interacción y como conjunto de procesos cuyo análisis remite indisociablemente a una gramática narrativa [el subrayado es nuestro] (en especial a una semiótica de la acción, de la manipulación intersubjetiva y de estrategia) y a una teoría de la enunciación» (pág. 281).

Para ello, ha sabido superar muy bien la repetición y el excesivo formalismo cientificista ad usum (GADEr, 1977, pp. 65-74) con un modelo sociosemiótico - no creemos que provisional- sobre manifestaciones discursivas de universos conceptuales de carácter colectivo muy complejos.

Por ello, debe reconocerse explícitamente la claridad con la que LANDOwSKI ha sabido interpretar su objeto de estudio, huyendo del vocabulario incomprensible y de los excesivos tecnicismos que sólo conducen al lector a entramados nocionales de escasa o nula utilidad ${ }^{14}$. Y si es verdad que, según los planteamientos greimasianos, la semiótica es una disciplina que está llamada por su propia naturaleza a servir para algo en la sociedad, no debe caberle ninguna duda al Dr. LANDOwsKi sobre la contribución - modesta o importante, no es éste el lugar adecuado ni yo el juez apropiado para establecerlo- de su sociosemiótica en el universo intelectual en que vivimos, puesto que La sociedad figurada. Ensayos de sociosemiótica, además de constituir un estudio serio sobre distintas realidades de nuestro momento, nos permite enriquecer el grado de comprensión del mundo que nos rodea y, lo que es más importante, reorientar la manera de interrogarnos sobre él.

12 Aunque también necesario, obviamente; vid. Lozano, Peña \& Abril, 1982, pp. 247 y ss.

13 De hecho, LANDowsKi ha sabido huir a la tentación de una actividad exclusivamente aplicada y de una interpretación pragmática de la lingüística de orientación social como un ámbito ajeno a la discusión teoricometodológica en el plano epistémico, recuperando la posición crítica y a la vez sintética ante el problema de la significación en el terreno social.

14 Incluso para facilitar la comprensión y la interrelación de aquellos términos que pudiesen ser complicados para el lector, LANDOwSKI sitúa al final del libro un índice analítico de estos tecnicismos usados a lo largo del volumen, y movido por su afán didáctico, invita al lector a la consulta de los mismos en Greimas \& CourTés, 1982 y 1991. 


\section{REFERENCIAS BIBLIOGRÁFICAS}

ACHARD, P. et alii (1983): Histoire et linguistique, Éd. de la Maison des Sciences de L'Homme, París.

BARTHES, R. et alii (1982): Análisis estructural del relato, Ediciones Buenos Aires, Barcelona.

BERRIO, J. (1983): Teoría social de la persuasión, Mitre, Barcelona.

BROWN, P. \& LEVINSON, S. (1987): Politeness, CUP, Cambridge.

CARABAÑA, J. \& LAMO, E. (1978): «La teoría social del interaccionismo simbólico», REIS, 1, Centro de Investigaciones Sociológicas, Madrid, pp. 159205.

CIFUENTES, J. L. (1990): «Sobre la homologación de semiótica y pragmática: a propósito de un soneto de Góngora», Estudios de Lingüistica Universidad de Alicante, 6, pp. 129-152.

CIFUENTES, J. L. (1994): Gramática cognitiva. Fundamentos críticos, Eudema, Madrid.

COSERIU, E. (1977): Principios de semántica estructural, Gredos, Madrid.

v. DIJK, T. A. (1980): Texto y contexto, Cátedra, Madrid.

DORRA, R. (trad.) (1993): «¿Greimas ha hecho semiótica? Conversación con Eric Landowski», Morphé. Ciencias del Lenguaje, $\mathrm{n}^{2} 8$, pp. 143-158.

DUCROT, O. (1984): El decir y lo dicho, Hachette, Buenos Aires.

GADET, F. (1977): «Théorie linguistique ou réalité langagière?»,Langages, 46, pp. 59-89.

GREIMAS, A. (1977): Semántica estructural, Gredos, Madrid.

GREIMAS, A. \& COURTÉS, J. (1982 y 1991): Semiótica. Diccionario razonado de la teoría del lenguaje, vol. I y II, Gredos, Madrid.

GUMPERZ,J.J.(1982):Discourse strategies. Studiesininterational sociolinguistics, Cambridge U.P., Nueva York.

HEGEL, G. (1983): «La evolución como concreción» apudIntroducción a la historia de la filosofía, Sarpe, Madrid, pp. 51-57.

HYMES, D. (1975): «Two types of linguistic relativity» apud W. Bright (ed.), Sociolinguistics, Mouton, La Haya, pp. 114-167.

JIMÉNEZ RUIZ, J. L. (1993): «Objetivismo y humanismo en el pensamiento social sobre el lenguaje», Lingüística. Revista de la Asociación de Lingüística y Filología de América Latina, $\mathrm{n}^{0} 5$-en prensa-.

JIMÉNEZ RUTZ, J. L. (1994a): «La trascendencia del sujeto lingüístico en la síntesis de unahermenéutica comprensiva del sentido»,Actasdel I Congreso de Lingüística General -en prensa-.

JIMÉNEZ RUIZ, J. L. (1994b): «Fundamentos epistémicos para una concepción sociolingüística de la historia de la lengua», Lexis, Vol. XVIII, 2, pp. 211-225. 
KORNBLIT, A. (1984): Semiótica de las relaciones familiares, Paidós, Barcelona. LÉVI-STRAUSS, Cl. (1976): Antropología estructural, Eudeba, Buenos Aires.

LOZANO,J.,PEÑA,C.\& ABRIL, G.(1982): Análisisdel discurso, Cátedra, Madrid.

LYONS, J. (1980): Semántica, Teide, Barcelona.

LYONS, J. (1983): Lenguaje, significado y contexto, Paidós, Barcelona.

LLEDÓ, E. (1975): Lenguaje e historia, Ariel, Barcelona.

MAINGUENEAU,D. (1987): Nouvellestendences en analyse du discours, Hachette, París.

MARTÍNEZ ARNALDOS, M.(1990):Lenguaje, texto ymass-media.Aproximación a una encrucijada, Universidad de Murcia, Murcia.

PARRET, H. (1983): Semiotics and Pragmatics, John Benjamins, Amsterdam.

PIZARRO, N. (1979): Metodología sociológica y teoría lingüústica, A. Corazón, Madrid.

RASTIER, F. (1991): Sémantique et recherches cognitives, PUF, París.

RASTIER, F. (1993a): «Tropos y semántica lingüística», Morphé. Ciencias del lenguaje, $\mathrm{n}^{\circ} 8$, pp. 53-83.

RASTIER, F. (1993b): «Complejidad semánticay contexto», Estudios de Lingüística Universidad de Alicante, $\mathrm{n}^{\circ}$ 9, pp. 25-42.

RÉCANATI, F. (1981): La transparencia y la enunciación, Hachette, Buenos Aires. SEARLE, J. R. (1979): Actos de habla, Cátedra, Madrid.

SLAMA-CAZACU, T. (1970): Lenguaje y contexto, Grijalbo, Barcelona.

SUMPF, J. (1968): «Linguistique et sociologie», Langages, 11, pp. 3-35.

TRUDGILL, P. (ed.), (1978): Sociolinguistic patterns of British English, Arnold, Londres.

VILLENA, J. A. (1992): Fundamentos del pensamiento social sobre el lenguaje, Ágora, Málaga.

VILLENA, J. A. (1993): «Conformismo y ciencia del lenguaje. La ideología del neutralismo lingüístico y la posición sociolingüística», Antiqua et nova Romania. Estudios lingüísticos y filológicos en honor de J. Mondéjar, Universidad de Granada, pp. 89-120. 